Review

\title{
Identifying Legal, Ecological and Governance Obstacles, and Opportunities for Adapting to Climate Change
}

\author{
Barbara Cosens ${ }^{1, *}$, Lance Gunderson ${ }^{2}$, Craig Allen ${ }^{3}$ and Melinda Harm Benson ${ }^{4}$ \\ 1 College of Law and Waters of the West, University of Idaho, Moscow, ID 83844, USA \\ 2 Department of Environmental Sciences, Emory University, Atlanta, GA 30322, USA; \\ E-Mail: lgunder@emory.edu \\ 3 U.S. Geological Survey, Nebraska Cooperative Fish and Wildlife Research Unit, \\ University of Nebraska, Lincoln, NE 68583, USA; E-Mail: allencr@unl.edu \\ 4 Department of Geography and Environmental Studies, University of New Mexico, \\ Albuquerque, NM 87131,USA; E-Mail: mhbenson@unm.edu \\ * Author to whom correspondence should be addressed; E-Mail: bcosens@uidaho.edu; \\ Tel.: +1-208-885-6298.
}

Received: 6 March 2014; in revised form: 14 April 2014 / Accepted: 14 April 2014 /

Published: 22 April 2014

\begin{abstract}
Current governance of regional scale water management systems in the United States has not placed them on a path toward sustainability, as conflict and gridlock characterize the social arena and ecosystem services continue to erode. Changing climate may continue this trajectory, but it also provides a catalyst for renewal of ecosystems and a window of opportunity for change in institutions. Resilience provides a bridging concept that predicts that change in ecological and social systems is often dramatic, abrupt, and surprising. Adapting to the uncertainty of climate driven change must be done in a manner perceived as legitimate by the participants in a democratic society. Adaptation must begin with the current hierarchical and fragmented social-ecological system as a baseline from which new approaches must be applied. Achieving a level of integration between ecological concepts and governance requires a dialogue across multiple disciplines, including ecologists with expertise in ecological resilience, hydrologists and climate experts, with social scientists and legal scholars. Criteria and models that link ecological dynamics with policies in complex, multi-jurisdictional water basins with adaptive management and governance frameworks may move these social-ecological systems toward greater sustainability.
\end{abstract}


Keywords: adaptive governance; ecological resilience; water law; sustainability; social-ecological system

\section{Introduction}

Water, in addition to its direct role in sustaining human life, supports ecosystems that provide many of the services upon which society relies. In order to provide these services, many water-based systems are heavily managed, with extensive infrastructure, multiple laws and regulations, and a complex set of institutions to govern these systems. Prior to intensive development, these systems were at one time characterized by dynamic ecosystems - riverine, riparian, wetland and terrestrial - that supported complex biodiversity. For millennia, humans have modified ecosystems to procure water that sustains human and ecological systems. During the 20th century, development of water systems accelerated, as dams and levees were constructed to reduce flood risk and provide water and energy for human activity, and this acceleration continues in developing nations [1]. Channelization and other constructs allowed for the movement of water to meet social demands for agriculture, urban development and economic growth. Land use changes within drainage basins have resulted in shifts in water quantity and quality, which in turn has altered ecosystem structures and functions. In short, development of water resources has led to ecosystems that are highly controlled and managed to meet specific social goals. Management of these systems has largely centered on controlling and stabilizing key ecological processes to achieve multiple social objectives. Such social objectives or expectations often reflect ethical, religious, aesthetic, and economic values and are achieved through translation into legal and engineered systems.

While our past and current governance of these major water systems has navigated competing interests with a manageable degree of conflict, even under a continuation of historic conditions the rate of erosion of ecosystem services is inconsistent with sustainability. Currently our management of these social-ecological water systems is challenged by uncertainty as we confront changes in climate, technology, energy supply, economics and human populations [2], as well as aging infrastructure. Already the separation of our system of governance from our understanding of ecological systems has reduced system capacity to respond to major hydrologic events such as flood and storm surge. Foreseeable acceleration in the major drivers of change in water basins requires parallel changes in water management and governance to enhance adaptive capacity and to integrate governance response with feedback from the ecological systems on which society relies. Changing climate is now the catalyst driving the call for an approach that integrates our understanding of the complex feedbacks between social and ecological systems with the need to manage in the face of high levels of uncertainty.

While climate change may accelerate the erosion of ecosystem services and increase the potential for conflict, it also presents a potential catalyst for change in policies or their application. The concept of resilience provides a roadmap for that response by forming the basis for a framework to bridge knowledge of the biophysical system with governance principles. Adaptation to climate change must be grounded in governance frameworks that allow for linking ecological dynamics to social ones. Broadly, we use the term governance to describe a process by which social expectations are developed 
and refined, implemented and executed through management actions [3,4], and include both the formal institutions reflected in our legal system and the informal processes and institutions that influence that system and the relevant power relationships [5]. We hypothesize that building adaptive capacity to climate change will require integrating the science of ecosystem dynamics with adaptive governance and that adaptive governance must include not only the aspects of governance that resilience scholars have observed to build adaptive capacity in management, but aspects of governance that facilitate legitimacy, equity and justice in governance in general if we are to consider the social system both sustainable and desirable. We base this hypothesis on ecological theories of resilience and panarchy [6], which have been proposed to explain transformative change in social-ecological systems and in an understanding of legal processes that have been theorized to facilitate good governance as developed in the following paragraphs.

Resilience is a measure of the amount of perturbation a social-ecological system can withstand while maintaining its structure and functions. Explicit to the concept of resilience is that a complex system can exist in alternative stable states, and that when resilience is exceeded, a critical threshold is crossed and structure and function will fundamentally change, sometimes in very unexpected and undesirable ways. Research to facilitate sustainability in major water basins must focus not only on ecological resilience, but also on how to maintain and foster resilience in a manner acceptable to society. Adaptive governance is a governance approach to foster ecological resilience through collaborative and participatory interactions among formal and informal institutions and learning based adaptive management $[3,5]$. Here, we add to it an understanding of the effect of that management on social resilience through consideration of legitimacy, power balance, and equal capacity to participate. We focus the application of our analysis on the water basins of North America to develop our theories in the context of highly developed and managed systems and to apply it to governance in a democratic society. In addition, this context forces us to consider recommendations for change in the context of fully developed legal systems, and thus the recommendations must take the current hierarchical and fragmented system as the baseline from which new approaches will be applied.

Governance and management of regional water systems are complex in both form and function. No single approach to adaptive water governance will achieve social goals, such as sustainability, in application to each unique social-ecological system defined by a water basin boundary. Elinor Ostrom and colleagues [7] have stated this eloquently; "In the context of governance of human-environment interactions, a panacea refers to a blueprint for a single type of governance system (e.g., government ownership, privatization, community property) that is applied to all environmental problems...Large studies of land-use and land-cover change have not found evidence for any single, ever-present driver of change. Experimental and field research has consistently found that individuals overtly facing the same situation vary substantially in their behavior... The track record of the use of panaceas is one of repeated failures."

Rather than propose a single overarching panacea, we propose to examine the ecological and legal dimensions of governance. By extracting a generalized framework from these forms of (adaptive) governance to guide the development of a set of legal tools, application of any of the tools may be tailored to meet local needs. In this way, the capacity of society to respond as the consequences of climate change unfold may be enhanced. By developing the framework and legal tools in the context of a selection of North American large-scale water based social-ecological systems representing a 
range of challenges in the face of climate change we seek to maximize the transferability to multiple settings and increase the probability that the tools developed have both practical application and the likelihood of adoption. This effort will contribute to the growing push to connect concepts from science to policy decisions and to move social-ecological systems toward greater sustainability. The first phase in that process, presented here, is to define and analyze the intersection between law, ecological resilience and adaptive governance in a few, but large, North American water basins. We begin by describing theories of transformative change and adaptive governance in the following section.

\section{Transformative Change in Social-Legal-Ecological Systems}

Management of large-scale water systems in the US is based upon legal frameworks that are predicated on specific assumptions of ecological structure and function [8]. Ecological theories that conceptualize change as linear and predictable are being replaced by concepts that explain abrupt, surprising and unpredictable ecological changes. A growing body of literature has begun to link legal and institutional frameworks with ecological models of resilience [9-16].

\subsection{Ecological Resilience}

We use the following definition of resilience as a bridging concept between policy and science to facilitate alignment of systems of governance with the complexity and non-linearity of social-ecological systems: "Resilience is a measure of the amount of perturbation a social-ecological system can withstand while maintaining its structure and functions; it describes the ability of a complex system to continue to provide the full range of ecosystem services in the face of change" [6,17-19].

Resilience literature has shown that social-ecological systems can exist in very different configurations or regimes, each with sets of reinforcing feedbacks and persistence over time $[19,20]$. Such alternative regimes can confer different sets of ecosystem goods and services. Ecosystem goods and services reflect the products of or work done by nature that serve society either directly or indirectly, such as provisioning of food or fiber, regulation of storms or floods, cycling of nutrients, among others [21,22]. For example, undammed or uncontrolled rivers provide many provisioning, regulatory, aesthetic and supporting services, such as flood abatement, nutrient and sediment transport, food production, and recreational experiences. Damming of rivers has often altered the ecosystem services by trading off services such as aesthetic and biodiversity supporting services to provide dependable engineered water and energy supplies or reduce vulnerability to flood risk. How to reconcile such tradeoffs consumes much of the current research and practitioners' debates. Since prior management activities have tended to reduce ecological resilience in favor of social stability and economic growth [23,24], scenarios of climate and other global drivers of change may lead to an increase in ecological regime shifts in the future.

We refer to ecological resilience as a systemic property that mediates transitions between alternative or alternating ecosystem configurations [17]. Different biological structures and processes characterize alternative states. As a system property, resilience is non-normative or value neutral. A system can be highly resilient either because it is quite adaptable (latitude) or quite resistant to change (resistance) [18]. Thus, an overgrazed field taken over by invasive weeds may be resistant to returning to its original state when livestock are removed-it is therefore resilient but not necessarily 
something we label as good. A brutal military dictatorship may be highly resistant to change - it is therefore resilient but not necessarily desirable. However, the social systems do make value judgments about alternative states. Indeed, much of the role of environmental governance is to contrast, weigh, and ultimately choose among alternative values of different ecological states. Thus, we find it more useful to discuss societal goals such as sustainability or the maintenance of ecosystem function, as an emergent outcome from a system of governance. What resilience brings to the discussion is a deeper understanding of how to adjust our actions in a complex system to achieve these goals.

In some cases, transitions among ecological states are fairly well understood. Many are discovered from long-term analysis of data sets, generally from monitoring data. Such state changes generally involve the interaction among a small set of variables and can be captured through models that use these data for parameterization. Such models and transitions cannot be compressed into simple metrics, but they can be captured for policy analysis through the use of simple ecological models. Moreover, defining an ecosystem state is relative to a particular set of spatial and temporal domains. Setting up the process for defining such regimes in complex water basins is provided in a subsequent section and will be used in application to six North American study basins in a second phase of this research. For purposes of this paper, examples will be drawn from four of those basins: the Florida Everglades; the Platte River; the Middle Rio Grande, and the Columbia River.

A second bridging concept from the resilience literature, panarchy, provides a dynamic cross-scale lens through which both social-ecological systems and their systems of governance can be viewed [6]. Panarchy describes the existence of systems in a nested, interconnected, hierarchy in various stages of growth, collapse, innovation and reorganization (Figure 1). Panarchy expands the concept of resilience by recognizing that: (a) resilience of a system declines as a system matures or develops; (b) the interaction of larger (slower) and smaller (faster) scale processes can foster resilience; (c) cross scale interactions may play a role in transformations into new regimes in both ecological and social system configurations; and (d) that resilience is a measure that can be applied to various scales because of the nested and hierarchical nature of self-organizing interactions. Such recognition leads to at least four features of change across scales; (1) Crises, (2) Revolts, (3) Recovery and Innovation and (4) Remember (as labeled in Figure 1). Crises can occur when broader scale processes (such as storms, droughts) create instability (omega), following a stable period of development, during which the system accumulated capital ( $\mathrm{r}$ to K phases). Revolts are used to describe smaller scale disturbances that can also create instability, which can propagate or cascade across spatial and temporal scales. The third focuses on the role that diversity and other forms of capital have on system recovery after a disturbance, a role that can seed novelty, trigger invasions, or spawn innovation in the next sweep of the adaptive cycle (omega to alpha phases). Another feature is the role of larger scale systems that provide resources to inhibit of that process of spreading (i.e., cross-scale collapse) or provide various types of memory (remember) from longer time scales (or larger geographic regions) that can sustain lower scale recovery. 
Figure 1. Panarchy theory emphasizes four key features of changes across scales in a social-ecological system. The four features are (1) Crises, (2) Revolt (3) Innovation and (4) Remember, and each intersect with different phases of an adaptive cycle.

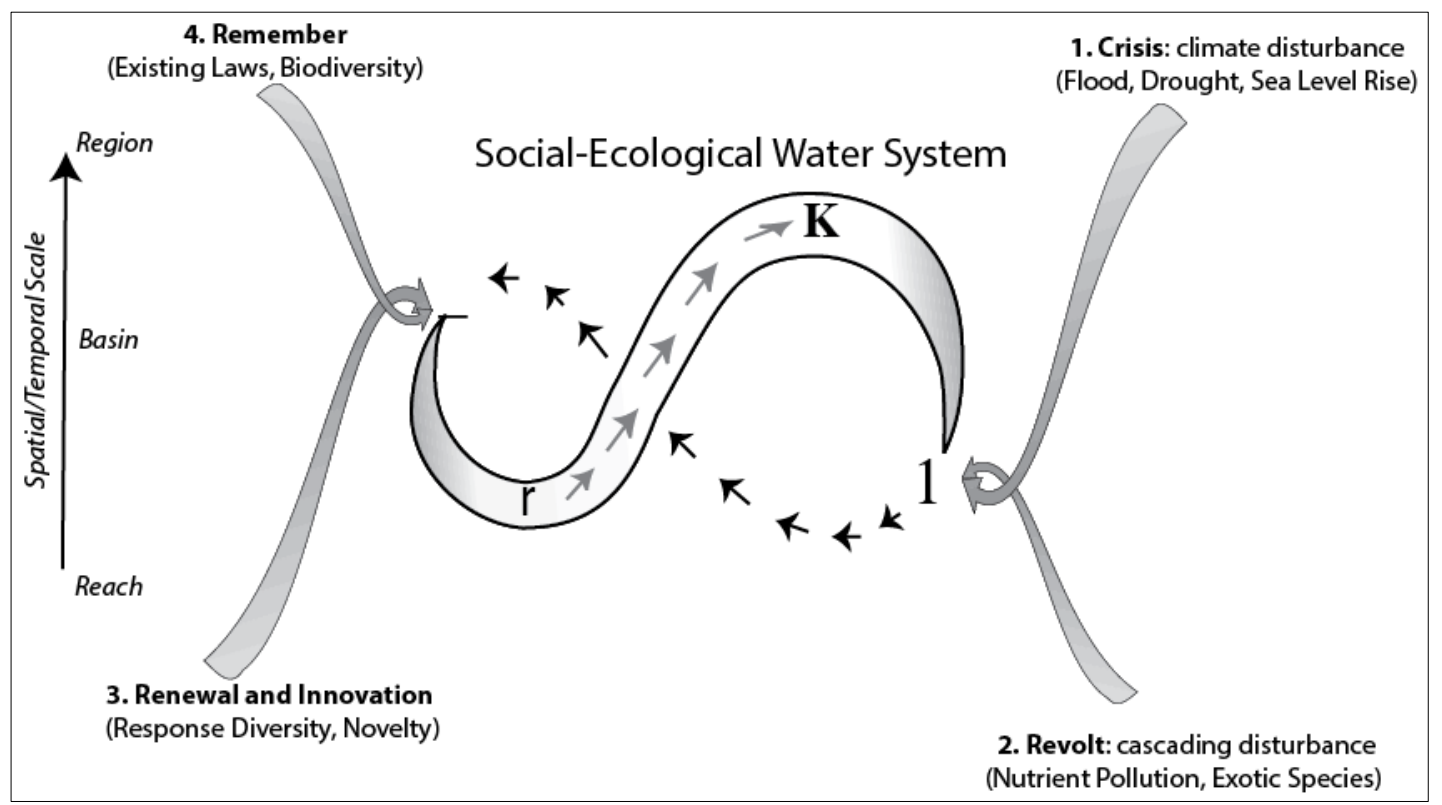

\subsection{Climate and Regime Shifts}

Broadly defined, climate is the result of long-term (decades to centuries) patterns of precipitation and temperature. In regional scale water systems, climatic patterns have been central to the design and management of such systems. For example, the Everglades region of Florida has a subtropical savanna climate; characterized by little seasonal change in temperature (rare freezing), with pronounced wet and dry seasons. During the wet summer season, most $(85 \%)$ of the annual rain falls, and the dry season continues through fall, winter and spring. As such, the management system has evolved to control flooding during the wet season, and to supply water to agriculture, urban interests and conservation areas during the dry season. In contrast, the Columbia and Platte River basins are defined by snow-dominated headwaters. In the Middle Rio Grande, snowpack storage is augmented by monsoonal rain events from July to September. Engineered storage combines with natural storage to hold water in the upper regions of the system in winter, moderate runoff to reduce flood risk, and allow release to maximize hydropower production and supply water to agriculture. In terms of the operation, both water systems are managed according to this annual cycle. As a correlated result, management of these regional water systems has modified ecosystem processes and structures, leading to ecological regime shifts in the provisioning of aquatic resources in the Columbia basin such that engineered support from hatchery production and fish transport is needed to sustain anadromous fish [25]. In the Platte River alteration of hydroperiod and reduction of flow variation requires costly and difficult human manipulation of critical sandbar habitat required by federally endangered migratory wildlife species. Middle Rio Grande faces similar challenges to the Platte River, with an extensive dam and levee infrastructure associated with flood control and water storage and allocation resulting in habitat degradation and biodiversity loss. 
How global drivers (including climate) intersect and influence regional scale water systems can be categorized according to the four types of abrupt change described in panarchy theory. These can be described in caricatures of (1) declining resilience, (2) rhythms of stability and instability, (3) cascading change and (4) windows of transformative change. Each is described briefly in the following paragraphs.

Resilience declines over time in many types of systems. Resilience is not a fixed property of systems, but rather changes as a result of many factors. This occurs in an adaptive cycle during the front loop ( $\mathrm{r}$ to $\mathrm{K}$ ) in Figure 1. When ecosystems develop and age, biomass (structure) increases to a plateau that is determined by the allocation of energy resources between growth and maintenance. The accumulated structure becomes more connected and vulnerable to disturbances. Severe storms, for example, can quickly destroy that structure, resulting in a long-term recovery. Floods in rivers can be viewed in a similar light. Current research suggests that the size and magnitude of many disturbance events (storms, fires and floods) are increasing as a result of changing climate. Of greater significance is that regardless of the size of a disturbance event, the increase of the impacts resulting from disturbance is linked to a decline in ecological resilience. As an example, in the past two years the United States has witnessed a dramatic increase in property damage associated with weather events. Such rising costs cannot be attributed to an increase in the magnitude and severity of weather events, but can be assigned, in part due to a decline in ecological buffering capacity. Such erosion of ecological resilience also occurs at regional scale systems as well [26]. Just as increasing interconnectedness and thus rigidity in the ecological system increases vulnerability, engineered services that rely on increasing efficiency to optimize select services are vulnerable to collapse following disturbance. For example, the fine balance among hydropower production, flood management, and flows required for fish currently achieved in the Columbia River basin leaves little room for adaptation when threatened by climate change effects that are already causing headwater basins to flip from snow to rain-dominated [27]. In the Middle Rio Grande, the current over allocation of water supply places severe constraints on system's capacity to provide environmental flows for endangered species reproductive habitat and cottonwood regeneration.

Many systems do not operate near a stable equilibrium, but rather undergo patterns of stasis and change as shown by the four phase adaptive cycle (Figure 1). Disturbances or instabilities are recurrent, and the system has evolved to survive such perturbations. In terms of resilience, this model of change includes systems that do not undergo a regime shift, but instead reorganize in a similar regime following a disturbance or period of creative destruction. Ecological examples include the pulse-stability model of riverine ecosystems [28], or wetland forests subject to multiple disturbances such as fire, floods, or cyclones. Democratic government systems undergo programed instabilities by virtue of their election cycle. In managing the ecological cycles of change, it is key to understand how climate influences the pattern of disturbances (i.e., increasing or decreasing frequency and magnitude of events) and how it influences the resilience of the system in terms of post disturbance recovery. Furthermore, institutional timeframes for coordination across jurisdictional boundaries such as the coordination of Columbia River management between the U.S. and Canada under the 1964 Columbia River Treaty [29], may no longer provide appropriate planning horizons when faced with the uncertainty of climate change [12].

Cascading change is a model that describes how small events can grow or increase in scale. Examples include ecological processes such as forest fires, pest and disease outbreaks, and 
eutrophication; social ones include events such as the Arab spring. In this model of change, positive feedbacks control the system dynamics such that disturbances or changes spread across space and time until either conditions change or the capital (or fuel) for such processes has been consumed. In terms of climate change, there are many scenarios whereby increasing temperature in the atmosphere may increase the release of more carbon or methane from accumulated storages, thereby leading to a runaway greenhouse effect. Cascading events are very difficult (if not impossible) to predict, posing difficulties for management and governance.

A growing body of literature indicates that social-ecological systems often undergo transformations of both the social and ecological components in an abrupt manner [6,30,31]. Many regional scale systems change as a result of specific events that can be ecological events such as severe storm or eutrophication events that can trigger changes not only in the ecological systems but in policy and governance [30]. Transformative change is thus indicated by the emergence of new or novel ecosystems or social systems or both [32]. Transformed ecosystems can be indicated by a regime shift in the structure and processes such as new trophic structures, or new dominant or diminished populations, as indicated by invasive species or endangered species. New social structures can be new forms of management or governance, and can be indicated by new institutions or policies. Indeed the history of development of the Everglades water management system has been interpreted by a series of transformations precipitated by floods, hurricanes, and droughts that revealed the failure of prior management and governance actions [30]. Climate change will likely provide opportunity catalyst for such transformations, as it will likely reveal failures in extant policy. It took an extreme and prolonged drought for example, to spur the recent legislative acknowledgement that surface waters and groundwater are interconnected in Nebraska, which has aided water management in the Platte Basin. In the Columbia basin, the transformation in governance to the international level under a 1964 treaty was in part catalyzed by an extreme flood event [29]. Some provisions of that treaty are expiring in the near future, which opens a window of opportunity and necessity for re-thinking international governance [33]. Coping with transformations, abrupt and unpredictable change as envisioned from shifting climates is the topic of the next section on adaptive governance. In the Middle Rio Grande, climate change and associated stresses on upland forest systems are predicted to produce a vegetative regime change. These changes will necessarily precipitate correspondingly transformative changes in water storage and flood control management strategies [34].

\section{Adaptive Governance}

Models of governance that incorporate social-ecological resilience and the ability to manage in the face of climate change must acknowledge and manage for high degrees of uncertainty. The theoretical proposition of multiple stable ecological regimes in ecosystems in the 1970's engendered the approach to resource management called adaptive management [35]. Adaptive management highlights the uncertainties of ecological changes and proposes a learning based approach to help navigate regime transitions. However, learning while managing has not been notably successful due in part to legal and governance constraints [36,37]. Adaptive governance has been recognized as the institutional and societal structures that facilitate adaptive resilience management [3]. To understand the difference between adaptive management and adaptive governance, it is useful to first explore the gaps that 
remain between the science-based call for adaptive management and its implementation in complex, multi-jurisdictional water basins.

First, adaptive management is a science-based, experimental approach that focuses on managing ecological transitions suggested by resilience theory. Resilience scholars note that behavioral shifts will be necessary for its implementation [3]. Human behavior, however, rarely changes simply because science indicates that a different approach is preferable. Instead, acceptance of decisions made by governance institutions requires legitimacy. Legitimizing adaptive management through governance (adaptive governance) is crucial to maintaining resilient and sustainable systems [38]. For example, an experimental approach to salmon recovery in the Columbia basin system that does not consider timeframes of adjustment relevant to planning associated with energy markets is unlikely to succeed. If adopted, the resulting destabilization of the social system would undermine its resilience despite potential gains in the ecosystem. Thus, adaptive management without governance considerations fosters resilience in the ecological system, but potentially at the expense of resilience in the social system.

Second, while adaptive management alone may be appropriate in situations in which a single institution governs the resource and a clear, narrow statutory goal has been set, hydrologic basins involve multiple scales of jurisdictional authority (Table 1), complex patterns of land ownership, and competing goals for water management that present a barrier to implementation of adaptive management without a system to account for this complexity. Hierarchical authority and fragmentation of governance both geographically and substantively pose barriers to adaptive integration of governance response [13]. Adaptive water governance requires a polycentric structure and capacity to respond at a bioregional scale [5]. Moving from the current system to a more adaptive form of governance will require legal authorities to form appropriate networks for adaptive responses and to develop bridging organizations where gaps occur, and authority for collaborative processes to establish goals for adaptive management.

Table 1. Management institutional matrix in water based social-ecological systems with large uncertainties associated with changing climate. Institutional approaches are related to multiplicity of social goals and management entities.

\begin{tabular}{ccc}
\hline & Singular Management Goal & Multiple Management Goals \\
\hline $\begin{array}{c}\text { Single Management } \\
\text { Entity }\end{array}$ & Adaptive Management & $\begin{array}{c}\text { Collaborative Adaptive } \\
\text { Management }\end{array}$ \\
\hline $\begin{array}{c}\text { Multiple Management } \\
\text { Entities }\end{array}$ & $\begin{array}{c}\text { Collaborative Adaptive } \\
\text { Management/Adaptive Governance }\end{array}$ & Adaptive Governance \\
\hline
\end{tabular}

Third, translation of adaptive governance into law must strike a balance between a prescriptive approach that unnecessarily constrains innovation and adaptation, and provision of the necessary authority to collaborate and respond adaptively. This requires careful attention to current system structure and adaptive capacity to provide legal authority and processes where lacking, and removing legal barriers that stand in the way of any emergent adaptive response. Research to identify criteria for self-organization in social-ecological systems has primarily focused on small indigenous communities and work remains to apply and develop the criteria in complex, highly managed systems [4]. The initial step to development of a framework and legal tools for adaptive water governance must be 
to examine select complex, regional scale, multi-jurisdictional water basins with hierarchical and fragmented approaches to management as to whether key ingredients for adaptive governance are present and functional.

\subsection{Components of Adaptive Governance}

While scholars have observed attributes of what is described as adaptive governance emerging in diverse natural resource management settings [3-5,39], many have also recognized legal barriers to the emergence of adaptive governance in highly managed systems [10,40]. Thus, the integration of law and resilience requires identification of legal barriers and opportunities as well as necessary legal tools for implementation of adaptive governance. We propose that governance that fosters resilience management in regional water basins has a small set of characteristics or components that must be fostered to achieve adaptive governance. These characteristics may be analyzed to identify the legal components that will lead to the development of legal tools that can be tailored to the needs of a particular water basin. Although more may emerge, preliminary research indicates that at least five aspects of governance are important in the development of legal tools to facilitate either the removal of barriers or the provision of authority for adaptive governance: structure, scale, adaptive capacity, power relations and legitimacy. Synthesis of the literature to define the characteristics of adaptive governance is more thoroughly covered in a recent article by Chaffin et al. [36]. We describe these minimal constituents in relation to the legal context necessary to implement them in the following paragraphs.

\subsubsection{Institutional Design and Structure}

The term governance encompasses: (1) the laws, policies and regulations involved in governing; (2) the governing institutions and institutional structure; and (3) the informal policies, practices, customs and power relationships that influence how governance plays out [3,5]. Thus, governance structures often consist of both formal and informal institutions. Response to environmental change, in particular regime shift, requires that a governance structure be in place that can respond to the specific type and scale of change despite high levels of uncertainty prior to its occurrence. Hierarchical structures with clear boundaries defining authority are, in general, poorly designed for the adaptive nature of the structure needed in the face of uncertainty. Instead, redundancy and overlapping authority at multiple levels are desirable. This type of structure has been described as polycentric in the resilience scholarship [5], and legal pluralism in the legal scholarship [41].

The legal challenge associated with the implementation of management of a connected water source by polycentric governance is to provide legal authority for cooperation and collaboration (1) without creating a highly inefficient and costly system of governance; (2) with sufficiently enforceable, substantive management goals and objectives; and (3) without knowing the scale and type of management issues that will arise. These challenges call for a flexible approach to coordination that is overlain on, rather than replacing, the existing governance structure. Institutional cooperation and collaboration is key to promoting adaptive and resilience based governance systems for confronting climate change [42-44]. A subset of the broader field of collaborative governance that is key to adaptive governance is the role of bridging networks $[45,46]$. Such networks link both formal and 
informal structures. These networks can be formed and supported by legal documents such as legislation, treaties or compacts, and include examples such as the Northwest Power Planning Council and the Columbia Basin Trust in the Columbia River basin, or Comprehensive Everglades Restoration Program. Others can be epistemic communities that focus on learning and governance, such as the Grand Canyon Adaptive Management Program. Some are advisory, and engage multiple stakeholders through formal channels. The emergence of informal bridging and shadow networks as gap fillers is a phenomenon that signals a degree of self-organization that may be exploited to achieve adaptive governance in basins where they exist. The role of law is to either provide the authority for their development where it is lacking, and get out of the way where such networks would emerge but for a legal barrier. Importantly, understanding of the current network structure among institutions in a specific basin, whether formal or informal, must be achieved prior to identification of the appropriate tailored approach to adaptive governance.

\subsubsection{The Role of Scale}

Scale captures the notion of fit of management and response to purpose [47], and the concept of subsidiarity (i.e., the concept that decisions should be made as close as possible to the individual citizen (see e.g., Article V of the Treaty Establishing the European Community). Fit can be qualitatively assessed by comparing the scale of function of a particular ecosystem service to the scale of governance related to that service [48]. Scale mismatch is more likely to be the rule rather than the exception for most natural resource problems. For example, national parks or state parks are established for conservation of biodiversity and recreational use, but usually represent a spatial subset of a larger ecosystem. River systems cover a wide range of scales; from international (such as the Columbia River basin) to multiple states (such as the Platte, Mississippi, or Missouri) to state-tribal (such as the Klamath and Columbia) to intrastate (such as the Altamaha in Georgia or the St. Johns in Florida). Importantly, even though many of these managed ecosystems are defined by fixed geographical or spatial scales, they are always subject to influence by ecological processes operating across different scales [49,50], including changing climate. Regional scale resource systems are managed at socially defined scales that may reflect history, culture, economics, politics or a myriad of other driving forces. Despite calls to match water governance to the basin scale, particularly in arid regions where water is the primary limiting factor for economic, radical modification of social boundaries is unlikely to occur. More importantly, despite connectivity of the water source, problems that arise in water governance may range from local to basin wide [51]. Rather than a one-size-fits-all approach to water governance, a mechanism to adapt response scale to the problem is needed. Both formal and informal networks across existing governing institutions may be one aspect of that mechanism. The role of law in network formation should be to provide authority for exchange of information and collaboration or to step aside when it creates barriers to such exchange.

In addition to scale matching, subsidiarity is a key principle in adaptive governance. Subsidiarity in this context refers to "a principle in social organization: functions which subordinate or local organizations perform effectively belong more properly to them than to a dominant central organization" [40]. It does not necessarily flow from the fact that a water basin is a connected hydrologic system that all decisions must be made at the basin scale. For example, local government 
must have a robust capacity to respond to crisis such as flood that may temporarily cut them off from outside aid. Local government is also the preferred scale for experimentation [11], and integration of local knowledge.

\subsubsection{Adaptive Capacity}

The importance of capacity to adapt and to participate cannot be overstated as a key component of adaptive governance to link social and ecological systems. In the context of the social system, adaptive capacity refers to the ability of the social system (broadly defined) to respond to ecological changes of state as identified in resilience theory. Identification of the existence of adaptive capacity includes both evidence of social learning and the authority to experiment and adapt [52]. Much of the adaptive capacity of a system involves the ability of the social system to manage uncertainties or conduct responsive programs such as adaptive management. This requires the capacity to integrate management actions that are structured as much for learning as for achieving social goals, the capacity to monitor appropriate ecological indicators, evaluate how systems respond to management actions, and to provide pathways and repositories for knowledge and experience.

Capacity, however, has a second important aspect in the context of the social system that is too often overlooked, and that is participatory capacity [11,38]. In panarchy theory, local adaptation and larger scale stability can allow a system to innovate without substantial disruption due to cascading or cross-scale collapse [6]. In governance, the concept of subsidiarity also suggests that moving decisions to lower levels on the jurisdictional scale is beneficial. Thus, much of society's ability to adapt quickly lies in the degree to which local systems of governance can learn and respond. Yet local government rarely has the human and financial resources to participate in natural resource decision making at the level of the state or federal government. In the United States, inverting the current flow of resources to the federal level to enhance capacity at the local level is a necessary precursor to the development of local capacity.

\subsubsection{Power Relations}

Much of governance is about managing power, defined as the capacity to, mobilize and control resources (both human and natural), to set and influence agendas, and to manage legitimacy [53]. Balance of power among competing water interests is a key component for achieving equity and justice in access to benefits from various ecosystem services. Empowerment of marginalized communities requires acquisition of the conditions that define power: "access to resources, strategies to mobilize them, skills to apply these methods and the willingness to do so in the pursuit of a specific goal" [54]. It can be assessed through evidence of relative participation in basin decision-making and can be enhanced through building the capacity to participate [55]. To date, many resilience-based assessments neglect the role power relations and historical inequities play within many social-ecological systems [56]. A more explicit and transparent attendance to disparities in current and historical allocations of power has the potential to build functional diversity and other adaptive capacity factors necessary for water governance systems. While other normative, psychological or moral frameworks are used to understand legitimacy [57] we discuss legitimacy in the context of legal frameworks for the process of decision making, as described in the next section. 


\subsection{Legitimacy}

Legitimacy is a qualitative term used here to describe the persuasiveness of the basis for a governmental action [58], and is further developed from an initial discussion by co-author Cosens [38]. It is a fundamental premise of political theory that people seek legitimacy in the actions of those who govern them. To be legitimate, a governmental assertion of authority must be both objectively justified and perceived to be justified [58]. While legitimacy is a feature of "good" governance and thus not a defining element of adaptive governance, it is a necessary legal consideration if democratic systems are to embrace adaptive governance. The rise of administrative agencies to implement natural resource management while arguably intended to enhance objective justification by infusing management with science, nevertheless challenges concepts of democratic legitimacy because actions taken by managers who are not elected officials may be perceived to lack legitimacy and lack direct accountability if in fact the science used lacks legitimacy. Administrative law has developed to address this issue [59]. Five sources of legitimacy have been identified as possible of implementation in administrative law [60], and each is an important consideration in the development of legal tools for adaptive governance.

\subsubsection{Results-Based Legitimacy}

Results-based legitimacy stems from the objectivity obtained through the use of scientific information as the basis for decision-making. Beginning with the National Forest Organic Act in 1897 (16 U.S.C. $\S \S ~ 473-478,479-482$ and 551, June 4, 1897, as amended 1905, 1911, 1925, 1962, 1964 , 1968 and 1976), U.S. federal and state land management has at its core a belief in the objectivity and superiority of science-based decision making. Yet increasingly, scientific expertise is questioned in areas of high scientific uncertainty in which science may be vulnerable to politicization [61-65]. Use of adaptive management as a tool for adaptive governance in situations of scientific uncertainty may, in fact, reverse this erosion of public confidence [66]. Although generally environmental management is undertaken with a goal in mind, the measure of compliance is frequently an agreed upon means to achieve that goal. Thus the implementation of a particular best management practice rather than its success in improving water quality becomes the measure of success of a water quality program. Adaptive management makes the goal the measure of success. Incremental adjustments to management actions are made based on feedback from monitoring to maintain progress toward the goal. The result of this approach is that both the incentive to manipulate data and the perception that it is being manipulated to point to the least painful management action are reduced.

\subsubsection{Order-Based Legitimacy}

Order-based legitimacy is derived from stability and predictability in decision-making. Our economic system in particular requires this aspect of legitimacy as a foundation for investment. More than any other area of legitimacy, the flexibility required for adaptation to change challenges order-based legitimacy. Yet, even with the current focus of our legal system on finality, resolution of environmental disputes that fails to achieve the anticipated outcome generally results in further conflict. Thus, finality in the face of ecological and climate change is a fallacy. At the same time, adaptive management is frequently implemented with biologic timeframes for change in mind, 
ignoring social stability. Instead, the focus must be on measured or incremental stability. Timeframes for adjustments in decision-making must reflect both the social need for stability and the balance between the timeframe necessary to measure meaningful ecologic change and the timeframe beyond which irreversible change may occur.

\subsubsection{Systemic Legitimacy}

Systemic legitimacy in the U.S. system is derived from the checks on agency action by the legislative and judicial branches, including the opportunity for judicial review of agency action (5 USC $\S 706)$. The networking of both formal and informal institutions of governance to share information, provide redundancy, and increase the ability to respond at the appropriate scale challenges the emphasis placed on clean lines separating jurisdictional authority in our current governmental hierarchy. Harmonization of rules, transparency in the flow and content of information, and attention to legitimacy in the use of non-governmental bridging organizations (see e.g., Federal Advisory Committee Act (FACA) P.L. 92-463; 5 U.S.C. App.), may address some of these issues.

\subsubsection{Deliberative Legitimacy}

Deliberative legitimacy is reflected in the growing expectation of public comment and dialogue in numerous aspects of agency decision-making. In the United States, the passage of the National Environmental Policy Act in 1969, can be considered the major turning point in public involvement in agency decision making [67], by placing the affirmative duty on agencies to develop, analyze, and provide to the public for comment, information on the environmental impact of major federal actions (U.S. National Environmental Policy Act 42 USC §4332). Key to robust deliberative legitimacy is capacity to participate. Legal rules that require collaboration or public input prior to decision-making are meaningless if those affected do not have the resources to engage.

\subsubsection{Procedural Legitimacy}

Procedural legitimacy is served by transparency that must be maintained even when working across jurisdictional lines and with non-governmental agencies. The Freedom of Information Act (Public Law 104-231, 5 USC §552) requires the documents developed by U.S. agencies be open to the public, provided on request, and the opening of meetings at which a decision might be made to the public (5 USC §552b). These requirements do not extend to non-governmental entities. Nevertheless, as long as actions by federal agencies are transparent, the flow of information across networks and input from non-governmental organizations should be sufficient to maintain legitimacy.

\section{Conclusions}

We argue that developing adequate and appropriate responses to climate change will require at least four integrated actions associated with the successful integration of adaptive governance principles. First, a qualitative characterization of extant range of ecosystem services and potential regime shifts should be made in case study basins. Second, models for adaptive governance of complex, multi-jurisdictional water basins can be developed using combined criteria of structure, scale, adaptive 
capacity, legitimacy and power alignments. Third, model administrative laws that facilitate development of networks and bridging organizations are needed to align the response scale of governance to the scale of the social-ecological changes listed above with increased flexibility for adaptive management in the face of uncertainty posed by climate change. The implementation of such models of change in both the ecological and social systems must be built on existing legal foundations, i.e., there must be a feasible way of transition to desired changes.

Ecosystems will change in the near future as a result of changing climate. Some of these changes will be predictable shifts in ecosystem services over space and time scales that can be managed in regional resource systems. Other types of change can be abrupt, unpredictable and transformative. The capacity to manage such changes will lie in our ability to proceed along frontiers of knowledge as to known and unknown regime shifts. The relationship between ecosystem states and ecosystem services is the lens through which models for governance will be developed, while recognizing that it is the system of governance itself that must choose which ecosystem services to sustain and manage. Processes are available to identify ecosystem services [68] and to determine scale mismatch between levels of authority and the scale of action needed to restore natural processes related to ecosystem services associated with flow regulation for flood risk reduction [48].

Model administrative laws to facilitate adaptive management and adaptive governance involve clear statutory goals and collaborative frameworks for achieving those goals. Craig and Ruhl [69] have recently released a draft model administrative law for adaptive management. Preliminary review suggests that while adaptive management alone may be appropriate when there are clear statutory goals (such as management of national parks or wilderness areas), a more collaborative approach that allows decisions on tradeoffs is necessary when goals are unclear or conflicting. Thus, in situations with multiple goals but clear lines of authority (such as management of national forests or BLM land) a hybrid of collaborative approaches and adaptive management may be necessary (Table 1). We call this collaborative adaptive management. In the context of river basins that involve mixed public and private land, multiple goals, competing uses and multiple jurisdictions, adaptive governance is necessary. Further refinement of this framework will allow identification of criteria for application of the appropriate track and model administrative laws to facilitate a tailored approach. Application to river basins must also consider whether existing law creates barriers to adaptive governance, and whether informal network formation may be more effective than a statutorily prescribed approach.

Earth's climate is already changing, and it is anticipated that it will continue to change in the next few decades in ways that have not been experienced by humans in recent history. The resulting changes in ecosystems can only be poorly foreseen or predicted. Therefore we must prepare flexible and adaptive frameworks for governance to cope with surprising futures. More closely integrating legal foundations with science, learning and adaptive governance that recognizes non-linear ecological changes will begin to build a capacity to adapt to sustainable futures.

\section{Acknowledgments}

This work was supported by the National Socio-Environmental Synthesis Center (SESYNC) under funding received from the National Science Foundation DBI-1052875 and is a product of the Social-Ecological System Resilience, Climate Change, \& Adaptive Water Governance Project. 
Gunderson received support from the US Army Corps of Engineers, Institute for Water Resources. It was also supported by the Tri-State EPSCoR Programs and funded by National Science Foundation \# NM 0814449. The Nebraska Cooperative Fish and Wildlife Research Unit is jointly supported by a cooperative agreement between the U.S. Geological Survey, the Nebraska Game and Parks Commission, the University of Nebraska-Lincoln, the U.S. Fish and Wildlife Service and the Wildlife Management Institute.

\section{Author Contributions}

Barbara Cosens and Lance Gunderson wrote the initial draft as a planning document for a SESYNC funded project. Craig Allen and Melinda Benson supplemented the ideas, examples and references for the final draft.

\section{Conflicts of Interest}

The authors declare no conflict of interest.

\section{References}

1. Graf, W. Dam nations: A geographic census of American dams and their large-scale hydrologic impacts. Water Resour. Res. 1999, 35, 1305-1311.

2. Ruhl, J. General Design Principles for Resilience and Adaptive Capacity in Legal Systems - With Applications to Climate Change Adaptation. N C Law Rev. 2011, 89, 1373-1401.

3. Folke, C.; Hahn, T.; Olsson, P.; Norberg, J. Adaptive governance of social-ecological systems. Annu. Rev. Environ. Resour. 2005, 30, 441-473.

4. Ostrom, E. A General Framework for Analyzing Sustainability of Social-Ecological Systems. Science 2009, 325, 419-422.

5. Huitema, D.; Mostert, E.; Egas, W.; Moellenkamp, S.; Pahl-Wostl, C.; Yalcin, R. Adaptive Water Governance: Assessing the Institutional Prescriptions of Adaptive (Co-)Management from a Governance Perspective and Defining a Research Agenda. Ecol. Soc. 2009, 14, 14:1-14:19.

6. Gunderson, L.H., Holling, C.S., Eds. Panarchy: Understanding Transformations in Systems of Humans and Nature; Island Press: Washington, DC, USA, 2002.

7. Ostrom, E.; Janssen, M.A.; Anderies, J.M. Going beyond panaceas. Proc. Natl. Acad. Sci. USA 2007, 104, 15176-15178.

8. Milly, P.C.; Betancourt, J.; Falkenmark, M.; Hirsch, M.; Kundzewicz, R.M.; Lettenmaier, Z.W.; Stouffer, R.J. Stationarity Is Dead: Whither Water Management? Science 2008, 319, 573-574.

9. Armitage, D. Resilience and Administrative Law. Ecol. Soc. 2013, 18, 18:1-18:2.

10. Benson, M.H. Intelligent Tinkering: the Endangered Species Act and Resilience. Ecol. Soc. 2012, 17, 28:1-28:8.

11. Cosens, B. Transboundary River Governance in the Face of Uncertainty: Resilience Theory and the Columbia River Treaty. Utah J. Land Res. Env. Law. 2010, 30, 229-265.

12. Cosens, B. The Columbia River Treaty Revisited: Transboundary River Governance in the Face of Uncertainty; Oregon State University Press: Corvallis, OR, USA, 2012. 
13. Cosens, B.; Stow, C. Resilience and Water Governance: Addressing Fragmentation and Uncertainty in Water Allocation and Water Quality Law. In Resilience and Law; Garmestani, A., Allen, C., Eds.; Columbia University Press: New York, NY, USA, 2014; pp. 142-175.

14. Ebbesson, J. Hey, Introduction: Where in Law is Social-Ecological Resilience? Ecol. Soc. 2013, $18,25: 1-25: 4$.

15. Garmestani, A., Allen, C., Eds. Resilience and Law; Columbia University Press: New York, NY, USA, 2014.

16. Garmestani, A.S.; Benson, M.H. A framework for resilience-based governance of social-ecological systems. Ecol. Soc. 2013, 18, 9:1-9:11.

17. Holling, C.S. Resilience and stability of ecological systems. Ann. Rev. Ecol. Syst. 1973, 4, 1-23.

18. Walker, B.; Holling, C.S.; Carpenter, S.R.; Kinzig, A. Adaptability and transformability in social-ecological systems. Ecol. Soc. 2004, 9, 5:1-5:8.

19. Walker, B.; Salt, D. Resilience Thinking: Sustaining Ecosystems and People in a Changing World; Island Press: Washington, DC, USA, 2006.

20. Gunderson, L.H.; Pritchard, L. Resilience and the Behavior of Large Scale Systems; Island Press: Washington, DC, USA, 2002.

21. Folke, C. Resilience: The emergence of a perspective for social-ecological systems analyses. Global Environ. Chang. 2006, 16, 253-267.

22. Folke, C.; Carpenter, S.; Walker, B.; Scheffer, M.; Elmqvist, T.; Gunderson, L.; Holling, C.S. Regime shifts, resilience, and biodiversity in ecosystem management. Annu. Rev. Ecol. Evol. Syst. 2004, 35, 557-581.

23. Holling, C.S. Surprise for science, resilience for ecosystems and incentives for people. Ecol. Appl. 1996, 6, 733-735.

24. Holling, C.S. From complex regions to complex worlds. Ecol. Soc. 2004, 9, 11:1-11:6.

25. Peery, C. The effects of dams and flow management on columbia river ecosystem processes. In The Columbia River Treaty Revisited: Transboundary River Governance in the Face of Uncertainty; Cosens, B., Ed.; Oregon State University Press: Corvallis, OR, USA, 2012; pp. 138-147.

26. Committee on Increasing National Resilience to Hazards and Disasters; Committee on Science, Engineering, and Public Policy (COSEPUP); Policy and Global Affairs (PGA); The National Academies. Disaster Resilience: A National Imperative; National Academies Press: Washington, DC, USA, 2012.

27. Hamlet, A.F.; Lee, S.Y.; Mickelson, K.E.B.; Elsner, M.M. Effects of projected climate change on energy supply and demand in the pacific northwest and washington state. Clim. Change 2010, 102, 103-128.

28. Palmer, M.A.; Lettenmaier, D.P.; Poff, N.L.; Postel, S.; Richter, B.; Warner, R. Climate change and river ecosystems: Protection and adaptation options. Environ. Manag. 2009, 44, 1053-1068.

29. Barton, J.; Ketchum, K. Columbia river treaty: Managing for uncertainty. In The Columbia River Treaty Revisited: Transboundary River Governance in the Face of Uncertainty; Cosens, B., Ed.; Oregon State University Press: Corvallis, OR, USA, 2012; pp. 43-49.

30. Gunderson, L., Holling, C., Light, S., Eds. Barriers and Bridges to the Renewal of Ecosystems and Institutions; Columbia University Press: New York, NY, USA, 1995.

31. Olsson, P.; Folke, C.; Hughes, T. Navigating the transition to ecosystem-based management of the great barrier reef, Australia. Proc. Natl. Acad. Sci. USA 2008, 105, 9489-9494. 
32. Allen, C.R.; Holling, C.S. Novelty, adaptive capacity, and resilience. Ecol. Soc. 2010, 15, 24:1-24:14.

33. Shurts, J. Rethinking the columbia river treaty. In The Columbia River Treaty Revisited: Transboundary River Governance in the Face of Uncertainty; Cosens, B., Ed.; Oregon State University Press: Corvallis, OR, USA, 2012; pp.175-248.

34. Williams, A.P.; Allen, C.; Macalady, A.; Griffin, D.; Woodhouse, C.; Meko, D.; Swetnam, T.; Rauscher, S.; Seager, R.; Grissino-Mayer, H.; et al. Temperature as a potent driver of regional forest drought stress and tree mortality. Nat. Clim. Change 2013, 3, 292-297.

35. Holling, C.S. Adaptive Environmental Assessment and Management; Wiley and Sons: London, UK, 1978.

36. Ruhl, J.B.; Fischman, R.L. Adaptive management in the courts. Minn. Law Rev. 2010, 95, 424-484.

37. Williams, B.K.; Brown, E.D. Adaptive management: From more talk to real action. Environ. Manag. 2014, 53, 465-479.

38. Cosens, B.A. Legitimacy, adaptation, and resilience in ecosystem management. Ecol. Soc. 2013, $18,3: 1-3: 3$

39. Chaffin, B.C.; Gosnell, H.; Cosens, B. The morphology of the social-ecological landscape: A decade of adaptive governance of natural resources. Ecol. Soc. 2014, submitted for publication.

40. Cosens, B.A.; Williams, M.K. Resilience and water governance: Adaptive governance in the columbia river basin. Ecol. Soc. 2012, 17, 3:1-3:14.

41. Roth, D.; Boelens, R.; Zwarteveen, M. Liquid Relations: Contested Water Rights and Legal Complexity; Rutgers University Press: New Jersey, NJ, USA, 2005.

42. Adger, W.N. Social capital, collective action, and adaptation to climate change. Econ. Geogr. 2003, 79, 387-404.

43. Adger, W.N.; Kelly, P.M.; Winkels, A.; Huy, L.Q.; Locke, C. Migration, remittances, livelihood trajectories, and social resilience. Ambio 2002, 31, 358-366.

44. Schlager, E.C., Engel, K.H., Rider, S., Eds. Navigating Climate Change Policy: The Opportunities of Federalism; The University of Arizona Press: Tucson, AZ, USA, 2011.

45. Bodin, O.; Crona., B. The role of social networks in natural resource governance: What relational patterns make a difference? Global Environ. Change 2009, 19, 366-374.

46. Lauber, B.T.; Decker, D.J.; Knuth, B.A. Social networks and community-based natural resource management. Environ. Manag. 2008, 42, 677-687.

47. Rijke, J.; Brown, R.; Zevenbergen, C.; Ashley, R.; Farrelly, M.; Morison, P.; van Herk, S. Fit-for-purpose governance: A framework to make adaptive governance operational. Environ. Sci. Policy 2012, 22, 73-84.

48. Cosens, B.; Boll, J.; Fremier, A.K. Adaptive governance and resilience: The Columbia river basin. Poster presentation at American Geophysical Union Fall Meeting, San Francisco, CA, USA, 3-7 December 2012.

49. Holling, C.S. The resilience of terrestrial ecosystems: Local surprise and global change. In Sustainable Development of the Biosphere; Clark, W.C., Munn, R.E., Eds.; Cambridge University Press: Cambridge, MA, USA, 1986; pp. 292-317.

50. Steele, J.H. Discussion: Scale and coupling in ecological systems. In Perspectives in Ecological Theory; Roughgarden, J., May, R.M., Levin, S.A., Eds.; Princeton University Press: Princeton, NJ, USA, 1978; pp. 177-180. 
51. Ruhl, J.B.; Salzman., J. Climate change, dead zones, and massive problems in the administrative state: Guidelines for whittling away. Calif. Law Rev. 2010, 98, 59-120.

52. Pahl-Wostl, C. A conceptual framework for analyzing adaptive capacity and multi-level learning processes in resource governance regimes. Global Environ. Change 2009, 19, 354-365.

53. Pritchard, L.J.; Sanderson, S.E. The dynamics of political discourse in seeking sustainability. In Panarchy: Understanding Transformations in Human and Natural Systems; Gunderson, L., Holling, C.S., Eds.; Island Press: Washington, DC, USA, 2002; pp. 147-169.

54. Avelino, F.; Rotmans, J. Power in transition: An interdisciplinary framework to study power in relation to structural change. Eur. J. Soc. Theor. 2009, 12, 543-556.

55. Gosnell, H.; Kelly, E.C. Peace on the river? Social-ecological restoration and large dam removal in the Klamath basin, USA. Water Altern. 2010, 3, 361-383.

56. Davidson, D.J. The applicability of the concept of resilience to social systems: Some sources of optimism and nagging doubts. Soc. Nat. Resour. 2010, 23, 1135-1149.

57. Tyler, T.R. Why People Obey the Law; Princeton University Press: Princeton, NJ, USA, 2006.

58. Bodansky, D. The legitimacy of international governance: A coming challenge for international environmental law? Am. J. Int. Law 1999, 93, 596-624.

59. Stewart, R. Administrative law in the twenty-first century. New York Univ. Law Rev. 2003, 78, 437-460.

60. Esty, D.C. Good governance at the supranational scale: Globalizing administrative law. Yale Law J. 2006, 115, 1490-1562.

61. Cosens, B. Resolving conflict in non-ideal, complex systems: Solutions for the law-science breakdown in environmental and natural resource law. Nat. Resour. J. 2008, 48, 257-301.

62. Doremus, H. Science plays defense: Natural resource management in the bush administration. Ecol. Law Q. 2005, 32, 249-305.

63. O'Reilly, K. Science, policy, and politics: The impact of the information quality act on risk-based regulatory activity at the epa. Buffalo Environ. Law J. 2007, 14, 249-287.

64. Ruhl, J.B.; Salzman, J. In defense of regulatory peer review. Wash. Univ. Law Rev. 2006, 84, 1-61.

65. Wagner, W.E. The science charade in toxic risk regulation. Columbia Law Rev. 1995, 95, 1613-1723.

66. Camacho, A.E. Adapting governance to climate change: Managing uncertainty through a learning infrastructure. Emory Law J. 2009, 59, 1-77.

67. Hirt, P.W.; Sowards, A.M. The past and future of the columbia river. In The Columbia River Treaty Revisited: Transboundary River Governance in the Face of Uncertainty; Cosens, B., Ed.; Oregon State University Press: Corvallis, OR, USA, 2012; pp. 115-136.

68. Walker, B.; Salt, D. Resilience Practice: Building Capacity to Absorb Disturbance and Maintain Function; Island Press: Washington, DC, USA, 2012.

69. Craig, R.; Ruhl, J.B. Designing administrative law for adaptive management. Vanderbilt Law Rev. 2014, 67, 1-87.

(C) 2014 by the authors; licensee MDPI, Basel, Switzerland. This article is an open access article distributed under the terms and conditions of the Creative Commons Attribution license (http://creativecommons.org/licenses/by/3.0/). 